\title{
Systemic Arterial Hypertensive Disorder
}

National Cancer Institute

\section{Source}

National Cancer Institute. Systemic Arterial Hypertensive Disorder. NCI Thesaurus. Code C102954.

Any condition resulting in systemically elevated blood pressure that is attributed to an arterial source. 